\title{
AS TÁTICAS SOCIOESPACIAIS DAS TRIBOS DE ÍNDIOS DO CARNAVAL DE NATAL (RN)
}

\author{
Valdemiro Severiano Filho (Unesa)
}

Associada à vida cotidiana, a cultura permeia o espaço enquanto marca e matriz. O objetivo do presente trabaIho é compreender a complexa rede de relações em que se encontram inseridas as tribos de índios do carnaval de Natal (RN), valorizadas pela experiência da escassez, da convivência e da solidariedade, cujas ações, duradouras ou efêmeras, enraízam-se no presente das agremiações, acionando mecanismos políticos, econômicos e simbólicos, e construindo redes sociais.

ESPAÇO, CULTURA, CARNAVAL, COTIDIANO.

SEVERIANO FILHO, Valdemiro. As táticas socioespaciais das tribos de índios do carnaval de $\mathrm{Na}$ tal (RN). Textos escolhidos de cultura e arte populares, Rio de Janeiro, v.11, n.2, p. 91-112, nov. 2014. 


\section{THE SOCIOSPATIAL TACTICS OF INDIANS TRIBES IN THE CARNAVAL OF NATAL (STATE OF RIO GRANDE DO NORTE/BRAZIL)}

Valdemiro Severiano Filho (Unesa)

Associated with everyday life, culture permeates the space both as trade mark and mold. The objective of this study is to understand the complex web of relationships in which Indian tribes are inserted in the carnival of $\mathrm{Na}$ tal/RN, enriched by the experience of scarcity, coexistence and solidarity with lasting or ephemeral actions rooted in the current situation of these associations, triggering political, economic, and symbolic mechanisms, and building social networks.

SPACE, CULTURE, CARNIVAL, EVERYDAY LIFE.

SEVERIANO FILHO, Valdemiro. As táticas socioespaciais das tribos de índios do carnaval de $\mathrm{Na}$ tal (RN). Textos escolhidos de cultura e arte populares, Rio de Janeiro, v.11, n.2, p. 91-112, nov. 2014. 
O presente artigo tem como objetivo analisar as tribos de índios do carnaval de Natal/RN e suas relações com o entorno, seguindo uma leitura hermenêutica das práticas socioespaciais, de modo a compreender a teia de significados que circunda as relações tecidas pelos indivíduos.

Ao tratar das tribos carnavalescas em perspectiva geográfica, é imprescindível identificar a dimensão espaçotemporal da manifestação em análise, que ocorre no centro urbano, projetando relações sociais vivenciadas na cotidianidade do bairro, forjando sentimento de pertença social, acionando perspectiva que aprecia as dimensões material e não material da cultura. Na análise, nos filiamos à nova abordagem cultural em geografia, para a qual as transformações em curso no espaço urbano devem ser contempladas como marca e matriz cultural (BERQUE, 1998), geradoras de cultura não homogênea.

Buscando discutir os agenciamentos espaciais que são observados nessas agremiações, a leitura das práticas ordinárias nos conduziu a importantes debates. Nesse sentido, temos que os "significados das diversas práticas espaciais associadas ao cotidiano, envolvendo as coisas correntes, e as manifestações menos frequentes ou periódicas estão, com raras exceções, a serem evidenciados pelos geógrafos brasileiros" (ROSENDAHL, CORRÊA, 2003, p. 17).

É certo que existe limitação na proposta empreendida, pois a dinâmica social - regras de conduta, comportamento, linguagem, valores e significados - modifica-se à proporção que se muda o lugar no qual enxergamos as práticas sociais. Se cada lugar - uma rua, uma praça, um bairro - é diferente quanto aos objetos e ações, tentar entender as dinâmicas espaciais das tribos no interior da cidade consiste em ação restrita e incompleta. Quero dizer com isso que as tribos carnavalescas não se diferenciam apenas espacialmente, mas, sobretudo, quanto à práxis cotidiana. Todavia, as semelhanças quanto à carência, escassez e ausência por que passam as comunidades em que estão inseridas nos possibilitam observar seus aspectos genéricos relevantes e suas particularidades.

Essa complexidade do espaço citadino enquanto matriz do urbano é de difícil apreensão se se pensar a cidade como um complexo símbolo que exprime uma tensão entre a racionalidade geométrica e o emaranhado de existências humanas. Cada ângulo seu nos permite visualizar uma determinada paisagem urbana, a depender das "lentes" de quem a vê e a vivencia, em seus diferentes sentidos, localidades, contextos e escalas.

É, pois, no bairro que a urbe se organiza, delimitando fronteiras e representando divisões em seu interior, congregando, em escala menor, um conjunto de objetos e ações, no qual as pessoas podem "ancorar as suas identidades na realidade circundante" (CLAVAL, 2003, p. 162). O bairro consiste no "lugar onde 
se manifesta um 'engajamento' social ou, noutros termos: uma arte de conviver com parceiros (...) que estão ligados a você pelo fato concreto, mas essencial, da proximidade e da repetição" (MAYOL, 1996, p. 39).

Os vínculos entre indivíduos são criados, principalmente, no bairro, por ser "o lugar de moradia que concentra as pessoas, permitindo o estabelecimento de relações mais personalizadas e duradouras que constituem a base da particular identidade produzida no espaço" (MAGNANI, 1998, p. 116). É nessa porção do espaço que "se elabora o sentimento de pertencimento ao 'lugar', espaço das práticas cotidianas e aparentemente banais" (SERPA, 2007, p. 10). Dozena (2011, p. 18) demonstra a importância do bairro em estudos de grupos carnavalescos, argumentando que nele se fomentam "as representações da vida urbana". ${ }^{1}$

Se por um lado percebemos nas cidades modernas - receptáculos do capital e da mercadoria - intensa urbanização diante do atual estágio por que passa o capitalismo, por outro, em seu interior, nos "pedaços" da cidade, podemos encontrar as inúmeras experiências banais da vida social - e aqui incluímos a relação das tribos de índios com o bairro - o que é visto com extrema beleza e desposado por nós como se fôssemos um flâneur baudelairiano. Reproduzimos o entendimento de que a vida cotidiana não se baseia tão somente na divisão do trabalho e nas instituições sociais, mas, sobretudo, em pequenos sistemas e realidades sociais cuja apropriação espacial produz campos simbólicos e práticas culturais.

Procuraremos, pois, entender a composição social, destacando elementos e ingredientes sociais mobilizados no contexto de duas tribos de índios - Tabajara e Gaviões-Amarelo - em seus respectivos ambientes urbanos, enquanto parte integrante do cotidiano. ${ }^{2}$

\section{A TRIBO DE ÍNDIOS TABAJARA E OS AGENCIAMENTOS SOCIOESPACIAIS}

O bairro Felipe Camarão, localizado na Zona Oeste da capital, é estigmatizado como local pobre e violento, não havendo a preocupação do poder público com o lazer na localidade, fato exemplificado pelo reduzido número de praças públicas e equipamentos desportivos. Essa situação é fruto do modelo de urbanização e desenvolvimento econômico adotado, fragmentador da sociedade e gerador de desigualdades socioespaciais.

O bairro foi formado a partir da antiga localidade denominada Peixe-Boi, que na década de 1960 foi loteada pelo proprietário da empresa Gerna, passando a ser chamado de Reforma. Em homenagem ao chefe indígena dos potiguaras, recebeu o nome de Felipe Camarão. 
A precária vida urbana das classes populares, principalmente na área da Zona Oeste da capital - que dispõe, entre outros problemas, de deficit imobiliário -, revela, também, a ausência dos equipamentos necessários à vida e garantidores dos direitos sociais estabelecidos constitucionalmente. Malgrado o "esquecimento" do bairro no que se refere à cultura e ao lazer pelos órgãos públicos, os moradores, voluntariamente, desenvolvem atividades que revelam a espontaneidade e a solidariedade, tais como grupos de capoeira, escolas de futebol, quadriIhas juninas e, mais especificamente, a tribo de índios de carnaval Tabajara. Nesse sentido, entendemos que o desenho urbano das cidades modernas e sua estrutura social voltada para os ditames capitalistas valorizam determinados espaços - "luminosos" - e segregam outros - "opacos" -, mas que, por força da criatividade e solidariedade de seus agentes hegemonizados, produzem cultura:

A gente trabalha pro carnaval; quando termina o carnaval, a gente faz um outro trabalho para o São João; nós trabalhamos com o balé popular de Natal. Num é um balé clássico, é um balé popular resgatando as nossas danças, as nossas raízes, como Araruna, como coco; vem num pacote só; então a gente faz esse trabalho até dezembro" (PAULO LIRA - presidente da tribo de índios Tabajara).

Felipe Camarão "respira" uma cultura realizada pela própria comunidade, e a tribo Tabajara contribui para essa vivência cultural e folclórica formando um conjunto fundamentado pela "inscrição social, pela espacialização e pelos mecanismos de solidariedade que são seu corolário" (MAFFESOLI, 2000, p. 33), acionando estruturas sociais vividas na cidade.

Além dos valores comunitários, percebe-se um envolvimento familiar na cultura popular do bairro Felipe Camarão, passada de geração a geração, "na qual predominam valores de identificação, essenciais, que giram principalmente em torno de práticas de solidariedade" (MAYOL, 1996, p. 81).

Hodiernamente verificamos a imagem, reproduzida pelos meios de comunicação e pela própria ciência social, de um urbano ditado pelo capital, resumindo-se à mercadoria. Todavia, para além dessa perspectiva, encontramos, no cotidiano das pessoas, o lugar da descoberta e a escola da desalienação que as conduzem a outras práxis sociais, como os mecanismos de solidariedade dos participantes da tribo carnavalesca Tabajara:

Aqui eu preciso ajeitar pneu, alegorias; aí, à moçada que trabalha a gente tem que dar uma gratificação a um ou outro. (...) Porque eu tenho que aproveitar os meninos que estão ralando comigo" (PAULO LIRA - presidente da tribo de índios Tabajara). 
A preferência pelos "meninos" da agremiação demonstra relação que extrapola os limites da materialidade, evocando um elemento simbólico dessa primazia dos "de dentro" em relação aos "de fora", baseando-se numa rede de afinidade e proximidade:

por exemplo, a gente vai pro cortejo de Natal; nesse cortejo cada um vai ganhar 600 reais por cinco dias, só que no lugar de eu pegar pessoas de fora, eu prefiro pegar meus meninos aqui, que estão ralando comigo, filhos deles, netos, que são pessoas que sempre estão comigo" (PAULO LIRA - presidente da tribo de índios Tabajara).

A diferença entre os insiders e os outsiders aciona uma alteridade e impõe um limite entre aqueles que estão dentro e fora do círculo relacional. Há uma relação de proximidade em que o morador do bairro e participante do grupo compartilha e contribui com as ações realizadas, forjando uma identidade territorial. Tal construção relacional no "estar próximo" é um componente da vida social, denominado por Maffesoli (2000, p. 169) proxemia, que liga os homens "a um território, a uma cidade, a um meio ambiente natural que partilho com outros. Estas são as pequenas histórias do dia a dia: tempo que se cristaliza em espaço".

A relação de proxemia na tribo de índios Tabajara possui lógica e éthos próprios, que ultrapassam a dinâmica capitalista do espaço reprodutor da mercadoria e do capital em direção a uma experiência horizontalizada do cotidiano, perpassando a corporalidade, a individualidade e produzindo socialidade (SANTOS, ago. 1996).

A valorização da cultura é levantada como uma espécie de finalidade da agremiação que tem como "palco" o bairro, sobrepondo vários usos, entre os quais o território das drogas, como colocado pelo presidente da agremiação:

Se o rapaz já tá morando numa comunidade que é violenta, nós não podemos passar justamente violência para aqueles componentes. A ideia é tirar esse jovem do tempo ocioso, pra que ele não fuja da cultura, não fuja do foco do que ele tá fazendo. Essas crianças quando começam a crescer dentro da cultura, dentro do esporte, fica mais difícil ele ir ao outro lado. Infelizmente as drogas se propagam todo dia aí" (PAULO LIRA - presidente da tribo de índios Tabajara).

A vida na sociedade é determinada, também, pelo "local proxêmico". Este "local" citadino - Felipe Camarão - possibilita inúmeros agenciamentos entre a tribo e seu entorno, de caráter econômico, social, simbólico, cultural e político, promovendo territorialidades peculiares ao bairro e que não se vinculam apenas ao domínio da produção: 
Eu estou me programando pra fazer um bingo no próximo mês, fazer um festival de prêmios, onde eu tenho uns amigos parceiros que ajudam na comunidade; por exemplo, tem um menino de uma loja que toda vez que eu vou fazer um bingo ele me dá um conjunto de estofado; o rapaz aqui, que tem 'Moto Peças', sempre me ajuda, mesmo quando ele tá meio 'aperreado', que não tem um brinde maior pra me dá, ele dá um ventilador, o rapaz da Ótica Esperança, do Mercadinho São Francisco, enfim, são parceiros da comunidade que vêm nos ajudando" (PAULO LIRA - presidente da tribo de índios Tabajara).

Os agentes situam-se em posições diferentes no interior do campo em que a estruturação do espaço social é determinada pelo capital. As condições precárias de funcionamento, impedindo a construção de locais próprios para a agremiação e contribuindo para as alocações marginais a que se submete a maioria das tribos - geralmente nos quintais das residências dos presidentes -, conduzem à necessidade de apoio, sobretudo financeiro, para a tribo de índios Tabajara. A condição de mendicidade possibilita uma práxis cotidiana, como a identificada na tribo em estudo, que conseguiu a cessão do desativado Clube de Mães Sali Farias com a contrapartida de efetuar os pagamentos de contas em atraso e assumir os subsequentes. Esse contexto de precarização social potencializa a rede de solidariedade tecida no local, como condição de resistência e sobrevivência da agremiação.

A relação entre a tribo de índios Tabajara e o comércio local, consubstanciada na ajuda mútua, dá-se mediante a incorporação de um mecanismo de contraprestação, estruturada na reciprocidade:

O de retorno é o seguinte: todos os eventos, independente de carnaval, de São João, todas as épocas, nós fazemos divulgações; (...) divulgamos o nome deles, na hora do bingo divulgamos. Nós sabemos que todo mundo planta uma bananeira, pois tá com interesse no cacho que aquela bananeira dá, então, no caso, as pessoas que nos ajudam, de qualquer forma, a gente dá um retorno em propaganda, divulgação" (PAULO LIRA - presidente da tribo de índios Tabajara).

O mecanismo de sociabilidade no bairro permite haver entre a tribo e o comércio essa mutualidade, baseada em práticas cotidianas que fogem ao controle rígido da racionalidade, fundamentada no être-ensemble como substrato da vida social, cujas ações, duradouras ou efêmeras, enraízam-se no presente da agremiação, e será, conforme Santos (1996, p. 318), "tanto mais intensa quanto 
maior a proximidade entre as pessoas envolvidas". Essa é, também, a compreensão de Marinho (2010, p. 63):

A socialidade, ${ }^{3}$ então, apreendida desta forma, remete-nos à tomada de um entorno da vida que, nas relações contraditórias do estar junto, propicia uma experiência de coexistência, de copresença, de codeterminação que conecta, pela capacidade dos indivíduos de produzir extensão e signos, os pedaços do território da vida (bairros, distritos, vilas, p. ex.) - que também são espaços de existência - ao espaço total da vida, o espaço de existência (a cidade, p. ex.).

Se, por um lado, os comerciantes promovem doações de objetos que serão utilizados pela agremiação para angariar recursos voltados para a produção do carnaval, por outro, a tribo carnavalesca divulga esses estabelecimentos comerciais circunvizinhos. Não se trata, a priori, de relação puramente comercial, mas de solidariedade que fortalece o laço de identidade comunitária, reforçando os valores mútuos de trocas simbólicas.

Todavia, ainda que a fundamentação do dar e retribuir não tenha conotação econômica aprioristicamente, se analisarmos com mais acuidade, conseguiremos transpor essa ideia de gratuidade nas trocas e verificar que, de fato, há uma ação econômica. $\mathrm{O}$ ato de doar mercadoria ou recursos não significa simples generosidade, pois, por mais que seja um comércio pequeno e local, ele se encontra inserido numa lógica de mercado e capital, e a divulgação constitui importante ferramenta para a comercialização dos produtos. Outrossim, quando os comerciantes da vizinhança contribuem para o carnaval da tribo, eles se beneficiam com o aumento da clientela oriunda dos participantes da agremiação: "Por exemplo, o menino da ótica: todo mundo que tá precisando fazer uns óculos, eu encaminho pra lá; ele também já faz um precinho mais acessível" (PAULO LIRA - presidente da tribo de índios Tabajara).

Existe uma rede social de vizinhança, expressa espacialmente pela tribo de índios Tabajara e o entorno do bairro Felipe Camarão. A rede serve de suporte para a vida social e possibilita que esse espaço seja apropriado pelos fluxos, como a "parceria" estabelecida entre a tribo e o comércio local, que aciona esses mecanismos comunicacionais e políticos. A relação de sociabilidade é, portanto, permeada e indissoluvelmente imbricada pelas esferas econômica e simbólica "economia das trocas simbólicas" - baseada na reciprocidade e instituída socialmente. Aqui pensamos a sociabilidade como:

a capacidade humana de estabelecer redes, através das quais as unidades de atividades, individuais ou coletivas, fazem circular as informações que exprimem seus interesses, gostos, paixões, opini- 
ões...: vizinhos, públicos, salões, círculos, cortes reais, mercados, classes sociais, civilizações (BAECHLER, 1995, p. 65-66).

Vemos, pois, que por intermédio da agremiação carnavalesca há uma rede submersa (VILLASANTE, 1996), pautada na informalidade e na cotidianidade, através de vínculos vicinais, que permite a construção de uma identidade social e define uma territorialidade materializada por essa rede de solidariedade. É de considerar que tal ocupação espacial coexiste com outras redes - sejam globais ou locais e que, de forma macro ou residual, se instalam nos lugares.

Percebemos interação e superposição entre essa rede submersa ou informal, criada a partir dos laços de vizinhança, parentesco e solidariedade, e redes locais que desenvolvem ações no bairro Felipe Camarão:

Sou voluntário do NAM, que é Núcleo de Amparo ao Menor e também faço com meu grupo quando precisa alguns trabalhos pra ajudar, porque nós precisamos também ajudar os menores, aquelas crianças nossas que vão crescendo. O NAM é um dos parceiros nossos, por exemplo, aqueles tambores de alumínio, ele que nos deu; quando nós precisamos de espaço para o ensaio, é uma forma daquela parceria que nós temos do espaço com eles, nós sentimos feliz porque nós ajudamos de um lado, recebemos do outro, e assim a comunidade vai crescendo e também vai melhorando" (PAULO LIRA - presidente da tribo de índios Tabajara).

O Núcleo de Amparo ao Menor é instituição beneficente do terceiro setor que desenvolve projetos no bairro, sobretudo nas áreas da educação, lazer, esporte e cultura, atendendo crianças e adolescentes em situação de vulnerabilidade. Tal necessidade de uma rede local vinculada aos movimentos sociais decorre da inércia do poder público e suas "redes de poder" (VILLASANTE, 1996) voltadas para a racionalidade hegemônica.

Outra importante ONG com atuação no bairro e que se relaciona com a tribo de índios Tabajara é a Fundação Fé e Alegria, pertencente a uma rede global com ação local, vinculada à Companhia de Jesus e à Federação Internacional do Movimento de Educação Popular Integral Fé e Alegria, com ações em vários países e estados brasileiros:

Tem a Fundação Fé e Alegria, que é outra parceira. De vez em quando conseguimos consultas de oftalmologistas com eles. No momento tá parado, mas a Fundação Fé e Alegria, quando recebe feijão da Mesa Brasil, ${ }^{4}$ eles também nos apoiam ajudando, pra que a gente distribua pra essas famílias esse feijão que vem do governo federal" (PAULO LIRA - presidente da tribo de índios Tabajara). 
A alimentação distribuída pela ONG Fé e Alegria não advém do governo federal, mas do Sesc, que é uma entidade sem fins lucrativos, mantida por empresários do comércio com vários projetos e programas com o objetivo de promover o desenvolvimento social, econômico e cultural da cidade. Para viabilizar a ação no bairro, a entidade estabelece parcerias com outras instituições, construindo uma rede local, ligando agentes locais, globais, formais e informais - com elos "fortes" e "fracos" com a comunidade, seguindo a tipologia de Putnam (1996) tais como o Sesc, a ONG Fé e Alegria e a tribo de índios Tabajara, formando um complexo de redes que entrelaça relações e contribui para a produção de capital social no interior do bairro. ${ }^{5}$ De acordo com Putnam (p.182), "toda sociedade (...) se caracteriza por sistemas de intercâmbios e comunicação interpessoais, tanto formais quanto informais".

Percebemos, assim, que a tribo de índios Tabajara e seu entorno realizam ações que acionam um aspecto solidário nas sociabilidades e mecanismos de ajuda mútua, valorizando o "estar junto" e estabelecendo uma rede social de vizinhança territorializada no bairro de Felipe Camarão.

\section{AS TÁTICAS SOCIOESPACIAIS DA TRIBO DE ÍNDIOS GAVIÕES- AMARELO}

Para compreender a complexa rede de relações (sociais, econômicas, políticas e simbólicas) desenvolvidas pelas agremiações indígenas, procuramos entender o funcionamento nos bastidores, iniciado, aproximadamente, três meses antes do carnaval, evidenciando "uma rede de significados e relações importantes no interior desses grupos carnavalescos, constituindo uma janela através da qual podemos espiar a vida de gente comum" (CUNHA, 2001, p. 189). E, para essa empreitada, é importante o lugar em que se estabelece a tribo, a partir da análise das suas interações e organização espacial.

Segundo a presidente da agremiação, a tribo de índios Gaviões-Amarelo foi fundada em 1983, tendo desfilado alguns anos no carnaval de Natal. Encontrava-se desativada até 2007, quando foi resgatada e "levada" para o conjunto Cidade do Sol, no bairro Igapó, Zona Norte de Natal:

A Gaviões-Amarelo estava morta há mais de dez anos. (...) Eu resgatei em 2007 pra 2008, através de seu Raimundo Brasil. (...) Seu Raimundo Brasil me fez essa proposta, se eu queria tomar conta da Gaviões-Amarelo; eu disse que não tinha condições nem sabia de nada sobre isso; aí, um amigo meu, que é da Tupi-Guarani, de São Gonçalo do Amarante, Paulo Sérgio, tinha me convidado pra dançar na dele, e eu dancei em 2006 na tribo dele, na Tupi-Guara- 
ni, gostei, adorei, e aí eu disse: 'não, eu não entendo de nada disso', aí ele disse: 'no começo eu te dou uma ajuda', (...) ele disse: 'você tem que arrumar umas pessoas', bem, então eu aceitei o desafio, e fui embora, né" (ZENEIDE DINIZ - presidente da tribo de índios Gaviões-Amarelo).

Assim como outras tribos de índios, a Gaviões-Amarelo não dispõe do principal espaço de organização social das agremiações carnavalescas: a quadra. No bairro "realiza-se grande parte do trabalho necessário a fim de se 'pôr o Carnaval na rua'" (MAIA, 2003, p. 198) e, para essa finalidade, é necessária a quadra enquanto "lugar central de atividades carnavalescas" (p. 199), com as funções de sede administrativa da agremiação, local de ensaio e espaço de atividades externas ao "mundo carnavalesco" (lazer, esporte, cultura, etc.). Ademais, na quadra se podem angariar recursos, com a realização de festas, apresentações e "ensaios gerais".

Pela inexistência desse objeto espacial, a residência da presidente tornase o lugar em que se realizam as reuniões e a confecção do material utilizado no desfile, sendo, ao mesmo tempo, sede administrativa e barracão, refuncionalizando o ambiente privado do quarto ao quintal. E a rua transmuda-se em local de ensaios e apresentações.

Os ensaios na rua contribuem para maior visibilidade da tribo de índios na comunidade, possibilitando a forte relação com o conjunto Cidade do Sol e seus moradores. Essa é, pois, sua importância social para a comunidade. Realizamos um levantamento entre os integrantes da agremiação carnavalesca e verificamos a concentração de pessoas do bairro e da circunvizinhança, inexistindo integrantes residentes em outras regiões administrativas da cidade. Todavia, a entidade agrega pessoas de outros bairros da Zona Norte e municípios próximos: "Eu tenho pessoas do Golandim, tenho pessoas do Paraíso, tenho pessoas de Extremoz, tenho seis pessoas de São Gonçalo [do Amarante] que dançam com a gente" (ZENEIDE DINIZ - presidente da tribo de índios Gaviões-Amarelo).

Não obstante a presença de pessoas provenientes de outras localidades, sempre há um vínculo de parentesco ou de amizade, a exemplo das "pessoas de Extremoz" que são a filha, o genro e a neta da presidente da tribo. Quanto aos moradores do Golandim - distrito de São Gonçalo do Amarante - são, na verdade, os integrantes do Grupo de Capoeira Arte Negra do Mestre Carlos.

As relações de vizinhança, amizade e parentesco são os elementos principais que favorecem o desenvolvimento das atividades, vindo à tona quando buscamos o vínculo entre a tribo e seus integrantes. A tribo de índios é, pois, entendida como uma coletividade carnavalesca, uma associação espontânea constitu- 
ída por parentes, amigos e vizinhos, na qual verificamos o modo de expressar a vida social nesses laços.

O agrupamento deriva do influxo de amigos e familiares ou da vivência no bairro, exprimindo uma identidade grupal, cuja composição social é formada quase totalmente por pessoas das camadas pobres. Esse vínculo pode ser percebido nas palavras de Zeneide Diniz: "Os índios têm meus bichinhos pequenininhos, essa aqui é minha neta, ela começou aqui". Para ilustrar, vejamos o que pensa Eudes Silvestre, o feiticeiro da Gaviões-Amarelo:

Porque a minha mãe toma conta. Eu comecei com meu tio, mas tenho que ajudar minha mãe; a tribo é tudo na minha vida, eu sempre gostei e nunca vou deixar de gostar. Quando eu comecei a dançar nos índios, eu fui fazendo amigo. Tenho os amigos que jogam futebol, jogam capoeira. A tribo é uma coisa muito boa.

O feiticeiro, um dos papéis de destaque, é filho da companheira de Zeneide Diniz, Sandra Silvestre, tesoureira da agremiação. As três filhas da presidente da tribo também participam da tribo carnavalesca. Esse universo familiar ultrapassa as barreiras do grupo de carnaval, pois, antes de assumir a Gaviões-Amarelo, a família dançava na tribo de índios Tupi-Guarani, de São Gonçalo do Amarante, cujo presidente, Paulo Sérgio dos Santos, é irmão de Sandra Silvestre.

Observamos enfaticamente a coletividade construída em termos familiares e de amizade, sobretudo na transmissão de significados comuns no interior do grupo. O prazer e a satisfação que existe em ser membro da tribo de índios agregam valores, tais como a união familiar, cujo elemento mediador é a própria agremiação, ultrapassando a leitura estritamente concreta da realidade. Contextualizando hermeneuticamente essas relações, verificamos complexa teia de significados consubstanciada na solidariedade - seja no interior da agremiação ou entre ela e as outras - e no contexto social propício à convergência de relações familiares e comunitárias. São essas relações que vivificam a cidade, em suas múltiplas redes.

O significado da tribo de índios na própria vida de Zeneide Diniz é tão relevante, que, após a mudança de residência e, aliás, de município, a presidente, em poucos meses, retornou ao Conjunto Cidade do Sol. Para entidades como as tribos carnavalescas, a territorialização possibilita que desenvolvam suas atividades carnavalescas de modo a garantir a sobrevivência. Diante do vínculo vicinal assegurador da tradição, a mudança domiciliar ameaça a própria existência da agremiação, que é dependente dos laços proximais estabelecidos com os moradores do entorno. É interessante notar o fato de que, na escolha de moradia Zeneide Diniz sempre considera as dimensões da área externa da residência, vislumbrando 
o espaço para a construção das alegorias. Se, para a maioria das pessoas, o carnaval é um momento de diversão, para a responsável da tribo Gaviões-Amarelo, a festividade determina até mesmo o local em que irá residir.

Alguns agentes são produtos do universo social e cultural da tribo de índios, a exemplo da presidente Zeneide Diniz e suas filhas. Não obstante, verificamos vários graus de envolvimento com a agremiação. Enquanto uns apenas se predispõem a participar dos ensaios, outros "abraçam a causa" e ajudam na elaboração e confecção das fantasias e alegorias.

O sentimento de pertencer ao grupo é verificado na extrapolação das fronteiras carnavalescas para múltiplas ocasiões sociais, como aniversários e celebrações. Exemplo disso foi o ritual da capoeira realizado na sede do Conselho Comunitário com a participação dos integrantes não capoeiristas da tribo de índios. Tais ocasiões não limitam ou restringem os participantes para o desempenho das atividades sociais, sendo tênue a linha entre os domínios público e privado e ilimitado o grupamento social frequentador.

Pela inserção na comunidade, a tribo Gaviões-Amarelo, muito embora não disponha de um projeto social em virtude da ausência de capital e incentivo para a implementação, ela mesma, enquanto lócus de atividades sociais, constitui-se em uma ação social. Frequentar a agremiação é suficiente para que as pessoas se relacionem, sejam conhecidas ou não; fazendo ou renovando amizades.

A intenção da presidente da tribo, contudo, não é manter a agremiação como mera ação social, mas realizar projetos que sirvam aos componentes e ao público externo. Para que eles sejam colocados em prática, porém, são imprescindíveis os meios necessários ao pleno funcionamento, partindo de uma estrutura física para a realização:

O que eu queria mesmo era um canto assim, eu queria uma sede para os Gaviões. O que eu pretendo no próximo ano, ganhando, é comprar um terreno, nem que seja pequeno; fazer uma sede, um galpão grande para os Gaviões, porque nesse meio da tribo, é como eu the disse, tem as meninas que eu posso botar elas pra fazerem apresentações, tem as mães que eu posso botar até mesmo pra fazerem as fantasias, ensinar elas a fazer bordado, não ficar só nisso: tribo de índio. (...) Você tendo uma sede própria, tem os meninos da capoeira, eu posso pegar e tirar os meninos da rua, (...) pegar outras crianças que tá por aí. Vamos estudar, vamos fazer capoeira, vamos fazer danças, vamos fazer outras coisas, é o folclore, vamos fazer dança folclórica" (ZENEIDE DINIZ - presidente da tribo de índios Gaviões-Amarelo). 
É nesse sentido que a própria existência da agremiação carnavalesca na comunidade é um projeto social, por proporcionar momentos de encontro entre pessoas. E o almejo por melhores condições, sobretudo a quadra da tribo de índios, visando promover ações para a comunidade, reflete, em termos espaciais, um processo de estruturação social, pois a busca do espaço destinado ao grupo tem proporções que ultrapassam suas próprias necessidades e é carregada de intenções e valores, adentrando o universo espacial da psicoesfera (SANTOS, 1996).

Por esses momentos de compartilhamento no interior do grupo social, a tribo obteve a admiração da presidente do Conselho Comunitário do Conjunto Cidade do Sol, que colaborou para o desfile, sobretudo pela solicitação do Alvará para os ensaios na via pública junto ao órgão municipal competente e a participação no aluguel de dois ônibus para o traslado dos componentes ao desfile carnavalesco. Vejamos a declaração da presidente da tribo de índios: "Esse ano [de 2012] eu estou vendo que vai ser um pouquinho melhor porque tem a presidente do conselho comunitário [do conjunto Cidade do Sol], que esteve aqui na minha casa e disse que ia me ajudar no que puder" (ZENEIDE DINIZ - presidente da tribo de índios Gaviões-Amarelo).

É de observar dois dados importantes nessa relação entre o Conselho Comunitário e a tribo de índios Gaviões-Amarelo: a proximidade e o capital social. O primeiro, de ordem espacial, permitiu mais visibilidade da tribo pelo Conselho. A "sede" da agremiação - na época do carnaval de 2012 - e a residência da presidente do Conselho Comunitário localizam-se na mesma rua - Rua Marte -, o que contribuiu para a criação dessa rede relacional.

Aqui podemos recorrer a uma das propriedades do espaço público: a visibilidade. $\mathrm{O}$ espaço da rua gera um conjunto de ordenamentos que rege a copresença e queda visibilidade aos agentes. Os ensaios na rua promoveram uma cena pública capaz de permitir a visualização de "momentos da cidade" pelos moradores que se encontram e se reúnem, proporcionando valores positivos para a comunidade, definindo um compromisso moral, afetivo e de coesão social existente no interior do que Tönnies (1995) denominou "comunidade de 'lugar"' regida pela condição de vizinhança.

Além da admiração, o apoio dispensado pela representação política do conjunto à tribo de índios foi carregado de intencionalidades. O Conjunto Cidade do Sol atravessava, no início de 2012, momento político no qual grupos locais se organizavam para as eleições do Conselho Comunitário. Não podemos afirmar que a conjuntura política local foi determinante para o apoio da presidente - na época, presidenciável - à tribo Gaviões-Amarelo, contudo os votos dos integrantes da tribo favoreceram a vitória nas urnas e a reeleição de Judinéia Bel- 
chior. É nesse sentido que Bourdieu (2007) fala em lucros advindos das relações entre agentes.

A proximidade permitiu a construção de um capital social, isto é, um conjunto de recursos "que estão ligados à posse de uma rede durável de relações mais ou menos institucionalizadas de interconhecimento e inter-reconhecimento (...) cuja instauração e perpetuação supõem o reconhecimento dessa proximidade" (BOURDIEU, 2007, p. 67). A relação durável criada auxiliou nas trocas mútuas - materiais e simbólicas -, objetivadas, por exemplo, na ajuda da tribo para reeleger a presidente do Conselho Comunitário. Nesse aspecto, a concepção bourdieusiana de capital social se correlaciona com as ideias de sociabilidade (BAECHLER, 1995) e redes sociais (VILLASANTE, 1996) aqui propostas, tendo em vista que a rede se constrói nas ações recíprocas elevadas à esfera de interação social.

Essa rede social integra aspectos locais - a própria relação da associação de bairro com a tribo de índios - e globais - relação entre o Conselho Comunitário e políticos. A rede construída, contudo, assim como ocorre em quaisquer relações, pode, num caso de conflito, passar do adensamento da sociabilidade à sua rarefação, pois, afinal, trata-se de um campo de poder, objeto permanente de luta:

Judinéia nunca mais falou comigo, ela não sabe trabalhar, confunde as coisas; eu não posso confundir política com pessoas, porque, ela sempre apoiou Rogério Marinho, só que Judinéia não quis ver meu lado; eu sempre apoiei Cláudio Porpino" (ZENEIDE DINIZ - presidente da tribo de índios Gaviões-Amarelo).

Tal transposição ressalta o poder que as relações societárias, envolvendo todo o mundo social em contraposição às relações comunitárias, menores e menos adensadas - como um bairro, um grupo -, têm na sociedade urbana, o que se pode refletir na dinâmica intralocal do bairro. O discurso da "ajuda" foi suplantado pelo da "vantagem":

Ela não me ajudou em nada, ela não ia nem ver, poucas vezes ela foi filmar pra levar vantagem em cima da tribo, ela só quis levar vantagem em cima da tribo e eu não deixei que ela fizesse isso. (...) Agora na política ela queria que eu pegasse o pessoal da capoeira e colocasse dentro de um ônibus pra ir levar pra uma festa de Rogério Marinho e eu não fiz isso e ela ficou zangada comigo (ZENEIDE DINIZ - presidente da tribo de índios Gaviões-Amarelo).

Observamos a relação estabelecida entre a agremiação e dois grupos de capoeira da localidade em decorrência da dificuldade de componentes para o 
desfile carnavalesco. Esses agenciamentos verificados na tribo de índios constituem-se em táticas cotidianas, vinculadas às astúcias sutis das pessoas em seu cotidiano, sobretudo dos pobres:

Denomino, ao contrário, "tática" um cálculo que não pode contar com um próprio, nem portanto com uma fronteira que distingue o outro como totalidade visível. A tática só tem por lugar o do outro. Ela aí se insinua, fragmentariamente, sem apreendê-lo por inteiro, sem poder retê-lo a distância. Ela não dispõe de base onde capitalizar os seus proveitos, preparar suas expansões e assegurar uma independência em face das circunstâncias. O "próprio" é uma vitória do lugar sobre o tempo (CERTEAU, 1994, p. 46).

Entre as "táticas", verificamos os mecanismos de ajuda mútua que integram uma rede submersa existente entre a tribo de índios e os grupos capoeiristas. Mesmo com a presença de integrantes provenientes de outros locais, a agremiação não conseguiu, no Carnaval de 2012, a exemplo dos carnavais de anos anteriores, reunir o número mínimo exigido pelo regulamente e necessitou recorrer aos grupos capoeiristas para aumentar o número de brincantes. A "necessidade", portanto, permitiu o agenciamento: a tribo precisava de pessoas, e a capoeira, de material para confeccionar as roupas dos alunos.

Mestre Carlos garantiu a participação de 30 alunos no desfile da tribo de índios, que, por sua vez, acordou que cederia o tecido para serem confeccionadas 30 calças de capoeira. Tratou-se de um contrato tácito, firmado verbalmente, mas que, entre eles, tem validade, pela necessidade mútua. São sociabilidades construídas pela experiência da escassez, reino da necessidade, que atinge as camadas pobres da sociedade, mas que, por outro lado, garante a comunicação desses agentes. Nesse sentido, Santos (1996, p.260) coloca que nos guetos urbanos tende-se a dar às relações proximais "um conteúdo comunicacional ainda maior e isso se deve a uma percepção mais clara das situações pessoais ou de grupo e à afinidade de destino, afinidade econômica ou cultural".

O Grupo de Capoeira Arte Negra, do Mestre Carlos, realiza suas atividades na sede do Conselho Comunitário do conjunto, fruto da relação entre a presidente da tribo de índios com a presidente do conselho. A rede submersa - tribo de índios/grupo de capoeira - encontra-se imbricada com a rede local - tribo de índios/Conselho Comunitário - no interior do bairro, possibilitando maior interação entre a agremiação carnavalesca e a capoeira.

Com base no trabalho comunitário, a produção das fantasias e alegorias da Gaviões-Amarelo é realizada na "quadra" da agremiação, com estrutura improvisada no quintal da residência. É importante observar que se trata de espa- 
cialidade fluida, fluxa e mutável, pois acompanha a residência da presidente, com ela se confundindo nos meses que antecedem o carnaval. O barracão da GaviõesAmarelo estrutura-se nos moldes do "barracão de ala"6 de que fala Maia (2003, p. 202), conduzindo o universo do carnaval (rua, público) ao mundo doméstico (casa, privado):

A estruturação do barracão de ala concilia improviso e racionalidade. Comumente instalado no fundo do quintal, no terraço, ou no puxado feito especialmente para esse fim, seus locais de trabalho são divididos para melhor responder às etapas de produção das fantasias e adereços (corte e costura, bordado, colagem, sapataria etc.). Nada é desperdiçado, até mesmo as paredes e o teto servem para armazenar material, ou as próprias roupas, chapéus, adereços, etc.

Inexistem horários determinados para o trabalho na agremiação; o tempo destinado à confecção depende das atividades diárias das pessoas envolvidas, resultante de uma combinação do tempo "racional" - trabalho, afazeres domésticos, filhos - e do tempo "ocioso" - momento livre. As relações configuradas são, pois, perpassadas pelo modo de vida moderno e racionalizado, mas que, dialeticamente, define territorialidades decorrentes da prática cotidiana do bairro e criadora de uma atmosfera familiar e vicinal nos espaços de preparação do desfile - "formas associadas à produção cênica" (MAIA, 1999) - que "não só servem para integrar os participantes do evento e cultivar-Ihes um 'espírito de mobilização', como também constituem-se em opção de lazer e turismo (...) e empregam contingente significativo de mão de obra ociosa" (p. 206).

Não havendo regramento específico, apenas certa coordenação informal da presidente da tribo, vimos que se trata de subsistemas de solidariedade e cooperação promovidos no interior da agremiação, instalando na urbe divisões de trabalho típicas, que Santos (1996, p. 260) chamou de divisões proteiformes do trabalho, por serem "adaptáveis, instáveis, plásticas, adaptam-se a si mesmas, mediante incitações externas e internas. Sua solidariedade se cria e se recria ali mesmo".

Observamos que a rede de relações superpostas no interior da tribo de índios Gaviões-Amarelo possibilita o fazer carnavalesco por meio de táticas cotidianas, envolvendo sociabilidades, vínculos vicinais, de parentesco e amizade, desenvolvendo "maneiras de lidar com" (LÉVI-STRAUSS, 1989), ou seja, inúmeras ações e formas utilizáveis e adaptáveis, para a realização do carnaval. 


\section{CONSIDERAÇÕES FINAIS}

Buscamos no presente artigo compreender a complexa rede de relações existentes no contexto social das tribos de índios do carnaval natalense, resgatando os significados impressos nas territorialidades, sobretudo no uso do território e nas intencionalidades a eles inerentes, que esteiam táticas de cotidianidade.

Discutimos a participação de vários agentes, delimitando as posições e papéis nas ocasiões sociais geradas em torno do carnaval das tribos, revelando uma profusão de atividades que permitem uma leitura cultural do espaço, englobando aspectos políticos, econômicos e simbólicos, engendrando relações típicas do meio social, apontando para formações hierarquizadas e horizontalizadas no interior dos bairros, cujos mecanismos políticos relativizam e propõem uma leitura de menor abrangência e de diálogo, mas que guarda seu caráter de campo de forças.

Da prática carnavalesca emerge o sentimento de pertencimento ao grupo, calcado na vicinalidade e nas sociabilidades geradas, tecendo condições determinantes da vida social, pois possibilita uma tríplice função enunciativa: é um processo de apropriação, é uma realização espacial do lugar e implica relações culturais (sociais, políticas, econômicas e simbólicas). Se, para Certeau (1994), o caminhante atualiza a ordem espacial, o mesmo se pode dizer com relação às táticas cotidianas das tribos de índios, ao transformar o significante espacial, o que chamamos de refuncionalização dos objetos.

Enxergando o desfile - pensado de modo abrangente - como um ritual dramático, verificamos que as agremiações indígenas reforçam o bairrismo e os vínculos vicinais, inscrevendo uma identidade territorial com o bairro ou o município, por meio dos discursos que tendem a ser tratados com irrelevância nos estudos do mundo moderno, sobretudo quando se tenta compreender o urbano. Mas é justamente nesses momentos de festividades da sociedade brasileira que visualizamos o fenômeno de uma espécie de grupamentos humanos autênticos e espontâneos - as tribos de índios -, que dialogam com outros inúmeros agentes que compõem a sociedade, estabelecendo relações intermediadas pela cultura.

Muito embora exista uma racionalidade que conduz as pessoas, incluídas aquelas pertencentes às camadas populares, a outras formas de entretenimento e lazer no período carnavalesco, o carnaval tradicional do desfile de tribos de índios e escolas de samba, de certa forma, interessa a esses setores populares, pois, de algum modo, fala uma linguagem que eles aceitam e compreendem.

No interior dessa formação social, enfatizamo,s há uma existência social escapando da racionalidade hegemônica, inscrevendo outras temporalidades e 
territorialidades, numa multiplicidade de situações criadoras de uma riqueza material e imaterial, isto é, de cultura. Presentes estão, portanto, os três componentes do espaço urbano: sua morfologia (formas concretas), os comportamentos (maneiras de estar) e os significados dados às ações.

Essas experiências vislumbradas nas tribos de índios carnavalescas permitem-nos, concordando com Santos (2000), pensar que é necessária a continuidade dessas formas de lazer popular, aproximando-se da cultura que permeia os "de baixo" e não propriamente das atividades racionais e do capital.

Vivenciar o cotidiano em torno do carnaval das tribos de índios é vislumbrar procedimentos criativos que envolvem táticas do dia a dia, funcionando como uma verdadeira bricolagem, ao produzir novas formas-conteúdos através de objetos passados e finitos refuncionalizados. As bricolagens podem ser desde a apropriação das vias públicas, fazendo delas sua quadra de ensaio, até a confecção das alegorias e fantasias, em quintais de residências, reutilizando produtos, com a cooperação e ajuda dos participantes.

Por tais razões, entendemos que produzir o desfile carnavalesco remete a uma profusão de táticas e agenciamentos marcados pela negociação, reciprocidade e solidariedade, sob uma base identitária que conduz ao lugar em que se encontram estabelecidas estas tribos de índios, definindo aspectos territoriais, sociais e culturais.

Propusemo-nos compreender o carnaval das tribos de índios como um fato social, sob a análise geográfica, sem exaurir o assunto, mas lançando proposições e sugerindo novas discussões, sob perspectiva que une cotidiano, espaço e cultura.

\section{NOTAS}

1 Muito embora não seja o objetivo do presente trabalho, compreendemos, também, essa porção da cidade enquanto um espaço vivido cotidianamente, com lógica própria, caracterizado pelos arranjos, práticas sociais e representações simbólicas, compreensíveis pelo caráter topofílico - construído e vivenciado do bairro, cuja afetividade é propulsora da relação entre as pessoas e o lugar. Essa experiência do bairro implica "um espaço público que conjuga certa funcionalidade com uma inegável carga simbólica" (MAFFESOLI, 2000, p. 33).

2 Para a escolha das agremiações Tabajara e Gaviões-Amarelo, consideramos as sociabilidades que estabelecem com seu entorno e a receptividade encontrada, que foram preponderantes para a compreensão das minúcias na preparação do desfile; os dados foram coletados em observação participante. 
3 Frisamos que a concepção de "socialidade" em Marinho (2010) aproxima-se da "sociabilidade" e distancia-se da "socialidade" proposta por Baechler (1995), pois a "socialidade" para o geógrafo Samarone Marinho consiste na experiência do "estar junto", enquanto "socialidade" para o sociólogo Jean Baechler (1995, p. 66) é a "capacidade humana de manter coesos os grupos [sodalidade] e as redes [sociabilidade], de lhes assegurar a coerência e a coesão que os constituem em sociedades", designada por ele como uma "morfologia", isto é, realidades fundamentais da sociedade humana, a exemplo da cidade e da nação

40 Mesa Brasil é um Programa de Segurança Alimentar e Nutricional, realizado pelo Sesc, com ações educativas e assistenciais para o desenvolvimento comunitário. O projeto atende pessoas assistidas por entidades sociais em condição de vulnerabilidade social e nutricional.

5 No bairro Felipe Camarão há, ainda, a atuação da ONG Companhia TerrAmar, com o projeto Conexão Felipe Camarão, que realiza ações sociais, tais como oficinas de arte e música, e promove a cultura local, sobretudo as manifestações folclóricas, com incentivos e parcerias de grandes agentes sociais públicos e privados: Instituto Federal do Rio Grande do Norte - IFRN, Grupo Votorantim e Petrobras. Não há relação entre a tribo de índios Tabajara e a ONG, pois, de acordo com o presidente da agremiação, a instituição é fechada e restrita: "eles não convidam aquelas pessoas que trabalham com cultura no bairro" (PAULO LIRA - presidente da tribo de índios Tabajara).

6 "É o 'barracão de ala', localizado geralmente na casa dos chefes de ala, onde se confeccionam as fantasias masculinas e femininas de uma escola de samba. (...) O nome desloca para o mundo doméstico um termo, este sim, consagrado e dito seriamente, destinado a um outro universo: o barracão de escola de samba" (CAVALCANTE, 1984: 176).

\section{REFERÊNCIAS BIBLIOGRÁFICAS}

BAECHLER, Jean. Grupos e sociabilidade. In: BOUDON, Raymond. Tratado de sociologia. Rio de Janeiro: Zahar, 1995.

BERQUE, Augustin. Paisagem-marca, paisagem-matriz: elementos da problemática para uma geografia cultural. In: ROSENDAHL, Zeny; CORRÊA, Roberto Lobato. Paisagem, tempo e cultura. Rio de Janeiro: Eduerj, 1998.

BOURDIEU, Pierre. O capital social - notas provisórias. In: NOGUEIRA, Maria Alice; CATANI, Afrânio. Escritos de educação. Petrópolis: Vozes, 2007.

CAVALCANTI, Maria Laura Viveiros de Castro. Barracão de escola e "barracão de ala": breve estudo dos bastidores do carnaval. Revista do Patrimônio Histórico e Artístico Nacional, Rio de Janeiro, n. 20, 1984.

CERTEAU, Michel de. A invenção do cotidiano: artes de fazer. Petrópolis: Vozes, 1994. 
CLAVAL, Paul. A contribuição francesa ao desenvolvimento da abordagem cultural na geografia. In: ROSENDAHL, Zeny; CORRÊA, Roberto Lobato. Introdução à geografia cultural. Rio de Janeiro: Bertrand Brasil, 2003.

CUNHA, Maria Clementina Pereira. Ecos da folia: uma história social do carnaval carioca entre 1881 e 1920. São Paulo: Companhia das Letras, 2001.

DOZENA, Alessandro. A geografia do samba na cidade de São Paulo. São Paulo: Polisaber, 2011.

LÉVI-STRAUSS, Claude. O pensamento selvagem. Campinas: Papirus, 1989.

MAFFESOLI, Michel. O tempo das tribos: o declínio do individualismo nas sociedades de massa. Rio de Janeiro: Forense Universitária, 2000.

MAGNANI, José Guilherme Cantor. Festa no pedaço: cultura popular e lazer na cidade. São Paulo: Hucitec, 1998.

MAIA, Carlos Eduardo Santos. Ensaio interpretativo da dimensão espacial das festas populares. In: ROSENDAHL, Zeny; CORRÊA, Roberto Lobato. Manifestações da cultura no espaço. Rio de Janeiro: Eduerj, 1999.

. O lugar do bairro no mundo do samba. In: ALMEIDA, Maria Geralda de; RATTS, Alecsandro JP. Geografia: leituras culturais. Goiânia: Alternativa, 2003.

MARINHO, Samarone Carvalho. Um homem, um lugar: geografia da vida e perspectiva ontológica. Tese de Doutorado do Programa de Pós-Graduação em Geografia Humana, da Faculdade de Filosofia, Letras e Ciências Humana/USP, São Paulo, 2010.

MAYOL, Pierre. Primeira Parte: Morar. In: MAYOL, Pierre; GIARD, L. e CERTEAU, Michel de. A invenção do cotidiano: morar, cozinhar. Rio de Janeiro: Vozes, 1996.

PUTNAM, Robert D. Comunidade e democracia: a experiência da Itália moderna. Rio de Janeiro: Fundação Getulio Vargas, 1996.

ROSENDAHL, Zeny; CORRÊA, Roberto Lobato. Geografia cultural: introduzindo a temática, os textos e uma agenda. In: ROSENDAHL, Zeny; CORRÊA, Roberto Lobato. Introdução à geografia cultural. Rio de Janeiro: Bertrand Brasil, 2003.

SANTOS, Milton. A natureza do espaço: técnica e tempo, razão e emoção. São Paulo: Edusp, 1996.

. Por uma geografia cidadã: por uma epistemologia da existência. Boletim Gaúcho de Geografia. Porto Alegre, n. 21, p. 7-14, ago. 1996.

. Lazer popular e geração de empregos. In: Lazer numa sociedade globalizada. São Paulo: Sesc/World Leisure and Recreation Association, 2000.

SERPA, Ângelo. A trama das relações socioespaciais nos bairros populares de Salvador, Bahia. In: SERPA, Ângelo. Cidade popular: trama de relações socioespaciais. Salvador: EdUFBA, 2007.

TÖNNIES, Ferdinand. Comunidade e sociedade. In: MIRANDA, Orlando de. Para ler Ferdinand Tönnies. São Paulo: Edusp, 1995. 
VILLASANTE, Tomáz R. Metodologias dos conjuntos de ação. In: FISCHER, Tânia. Gestão contemporânea: cidades estratégicas e organizações locais. Rio de Janeiro: Fundação Getulio Vargas, 1996.

Valdemiro Severiano Filho é doutorando em ciências sociais, mestre em geografia e bacharel em ciências sociais pela Universidade Federal do Rio Grande do Norte, bacharel em direito pela Universidade do Estado do Rio Grande do Norte e docente dos cursos de graduação em Serviço Social e Gestão de Segurança Privada na Universidade Estácio de Sá - Unesa.

Recebido em: 20/04/2014

Aceito em: 27/06/2014 